\title{
Ductile-Phase Toughening of Brazed Joints
}

\begin{abstract}
N.R. PHILIPS, C.G. LEVI, and A.G. EVANS
A heat treatment is presented that uses ductile-phase toughening to mitigate the effect of brittle intermetallics in a Ni-based braze alloy. The fracture resistance has been enhanced by creating a microstructure containing elongated ductile $\gamma$-(Ni) domains that align, preferentially, across the joint. The development of this beneficial microstructure is based on an understanding of the transient dissolution, isothermal solidification, and coarsening phenomena. Due to slow kinetics, the elimination of intermetallics by diffusion is avoided in favor of ductile domain formation through solidification control. The toughening has been attributed to a combination of bridging and process zone dissipation, enabled by the ductile phase.
\end{abstract}

DOI: $10.1007 / \mathrm{s} 11661-009-9818-0$

(C) The Author(s) 2009. This article is published with open access at Springerlink.com

\section{INTRODUCTION}

BRAZING has experienced renewed interest for the fabrication of large-scale, lattice-based structures. These structures are being investigated for a wide range of applications, including blast resistance, ${ }^{[1,2]}$ shape morphing, ${ }^{[3]}$ ultra-lightweight, ${ }^{[4]}$ and active cooling. ${ }^{[5]}$ The fabrication of such multifunctional structures involves bending thin core members and bonding to thin faces. ${ }^{[6]}$ For topologically complex systems, welding is often not feasible and brazing is the preferred option. Many such structures comprise corrosion-resistant steels that require brazes incorporating nonmetallic modifiers and melting point depressants ( $\mathrm{Si}$ and $\mathrm{P}$ ). These elements react with the steel to form brittle intermetallics, resulting in low toughness $\left(\Gamma \approx 1 \mathrm{~kJ} / \mathrm{m}^{2}\right) \cdot{ }^{[7]}$ For the most commonly used Ni-based braze alloys, the strategies typically employed to minimize intermetallics and obviate brittleness (transient liquid-phase bonding or wide gap brazing $)^{[8,9]}$ are not viable for the intermediate width (75 to $200 \mu \mathrm{m}$ ) attachments present in lattice structures.

An alternative strategy applicable to intermediate thickness joints derives from the following understanding of microstructure evolution in the braze. ${ }^{[10]} \mathrm{A}$ $\gamma$-(Ni) phase (the ductile constituent) solidifies isothermally onto the steel substrate in a two-stage process: a rapid dissolution $\leftrightarrow$ reprecipitation reaction in which the steel is consumed and $\gamma-(\mathrm{Ni})$ deposited, followed by a slower solid-state diffusion reaction in which the braze modifiers are diluted into the bulk. This process segregates the nonmetallic components to the center, resulting in the formation of continuous intermetallic microconstituents upon solidification during

N.R. PHILIPS, Doctoral Candidates, and C.G. LEVI and A.G. EVANS, Professors, are with the Materials Department, University of California, Santa Barbara, CA 93106-5050. Contact e-mail: nphilips@engr.ucsb.edu

Manuscript submitted August 12, 2008.

Article published online April 15, 2009 cooling. The braze solidification sequence may thus be expressed as ${ }^{[10]}$

$$
\begin{aligned}
L & \rightarrow L+\gamma \rightarrow L+\gamma+T \rightarrow L+\gamma+T+M_{2} P \\
& \rightarrow \gamma+T+M_{2} P
\end{aligned}
$$

indicating that primary $\gamma$-(Ni) forms from the liquid $(L)$ at the liquidus, followed by divorced co-precipitation with the silicide ( $T$ phase), and finally the terminal pseudo-eutectic solidification of the phosphide $M_{2} P$ with $\gamma$-(Ni). The pseudo-eutectic $\gamma$-(Ni) forms a continuous ductile network throughout the joint, which forms bridging ligaments upon fracture that undergo significant plastic stretch. The associated plastic dissipation provides about half the toughness. ${ }^{[7]}$ The detrimental influence of the silicide can be negated by dilution, but the phosphides persist due to their limited solubility in the $\gamma$-(Ni) and steel substrate. ${ }^{[10]}$ The foregoing sequence suggests that heat treatments could be designed that redistribute the $\gamma$-(Ni) to the centerline, thereby disrupting the continuous intermetallics and enhancing ductilephase toughening. To explore this possibility, the dissolution and evolution of solidification reactions are investigated for a quaternary braze alloy containing both Si and P (Nicrobraze 31: Wall-Colmonoy, Cincinnati, $\mathrm{OH})$ with austenitic stainless steel substrates (Table I).

To provide focus, recall that the bridging mechanism of ductile-phase toughening, $\Delta \Gamma_{s s}$, scales with the diameter, $2 R$, and the area fraction, $f$, of this phase intercepted by the crack: ${ }^{[11-14]} \Delta \Gamma_{s s}=f R \chi$, where $\sigma_{o}$ is the yield strength of the ductile phase and $\chi$ is a work of rupture parameter governed by the plastic stretch, $u_{c} \rightarrow \chi=2.5 u_{c} / R^{[11-14]}$ Note that, to maximize the contribution to this toughening mechanism, the ductile phase should percolate through the joint, so that the area fraction term, $f$, participates fully. Otherwise, the crack circumvents this phase and obviates the toughening. ${ }^{[14]}$ To exploit this opportunity, fabrication procedures that increase the product $f R$ are pursued. Namely, the mechanisms of dissolution and isothermal precipitation are investigated, followed by the design of heat 
Table I. Composition (Atomic Percent) of Braze and Substrate Alloys

\begin{tabular}{|c|c|c|c|c|c|}
\hline Alloy & $\mathrm{Ni}$ & $\mathrm{Cr}$ & $\mathrm{Si}$ & $\mathrm{P}$ & $\mathrm{Fe}$ \\
\hline Nicrobraze 31 & 59 & 21 & 12 & 7 & 0 \\
\hline $304 \mathrm{SS}$ & 7.5 & 19 & 0.7 & 0 & 70 \\
\hline $303 \mathrm{SS}$ & 10 & 19 & 1.3 & 0 & 68 \\
\hline
\end{tabular}

treatments capable of appropriately modifying the microstructure. Thereafter, the fracture resistance of the resulting joints is measured and the toughening analyzed.

\section{SOLIDIFICATION SEQUENCE}

\section{A. Methods}

To simulate dissolution of the substrate, thermal analysis specimens were synthesized from Nicrobraze 31 and 303 stainless steel powders by melting mixtures at $1250{ }^{\circ} \mathrm{C}$ and cooling at $2{ }^{\circ} \mathrm{C} / \mathrm{min}$. Dilutions were made from 1 to $20 \mathrm{wt}$ pct 303 stainless steel $\left(w_{S}\right)$. Thermal analysis was carried out in a differential scanning calorimeter (DSC 404 C Pegasus: Netzsch Instruments, Capitola, CA) at heating and cooling rates of $2.5^{\circ} \mathrm{C} / \mathrm{min}$ in a gettered argon atmosphere $\left(P_{\mathrm{O}_{2}}<10^{-12} \mathrm{~atm}\right)$. To establish the primary solidification product, a subliquidus quench was performed by slowly cooling an encapsulated molten alloy specimen through the liquidus temperature before quenching in water.

Braze evolution was examined within a fixed width slot $(125 \mu \mathrm{m})$ in a 304 stainless steel specimen (Figure 1), bright annealed to recrystallize the recast surface layer created by electrodischarge machining. The powdered braze alloy was placed in a reservoir adjacent to the slot and sintered at $900{ }^{\circ} \mathrm{C}$ to fix the powder and remove the organic binder. Samples were brazed for several hours at $1100{ }^{\circ} \mathrm{C}$ after heating at $10^{\circ} \mathrm{C} / \mathrm{min}$. To differentiate isothermally formed $\gamma$-(Ni) from that formed upon cooling, specimens were quenched from the hot zone by dropping into a graphite crucible

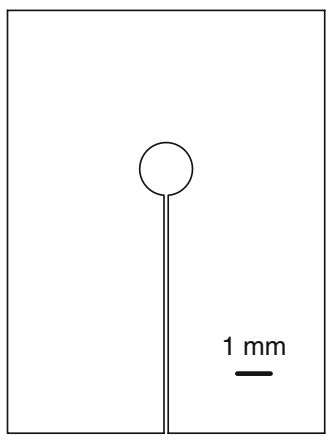

(a)

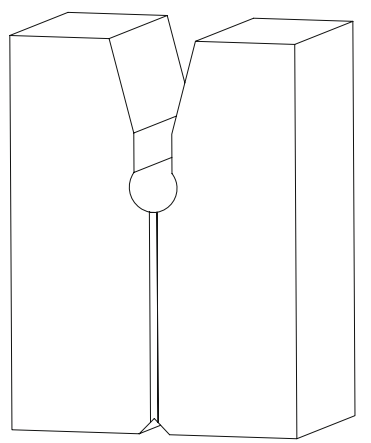

(b)
Fig. 1-Brazed joint configuration. (a) A $125-\mu \mathrm{m}$ notch is machined to create a fixed width braze joint to study recession, dissolution, and toughness. (b) For mechanical testing, additional notches are cut out to allow for loading with a $\mathrm{Si}_{3} \mathrm{~N}_{4}$ wedge. at room temperature. The phase compositions were characterized by electron microprobe analysis using calibrated standards.

\section{B. Measurements and Interpretation}

The DSC analysis (Figure 2(a)) and microstructure resulting from a subliquidus quench (Figure 3 ) not only confirm the initial three-step solidification sequence in the undiluted braze, but also reveal that after 19 pct dilution, the secondary silicide and terminal pseudoeutectic reactions coalesce, yielding a nominally twostage process:

$$
L \rightarrow L+\gamma \rightarrow L+\gamma+T+M_{2} P \rightarrow \gamma+T+M_{2} P
$$

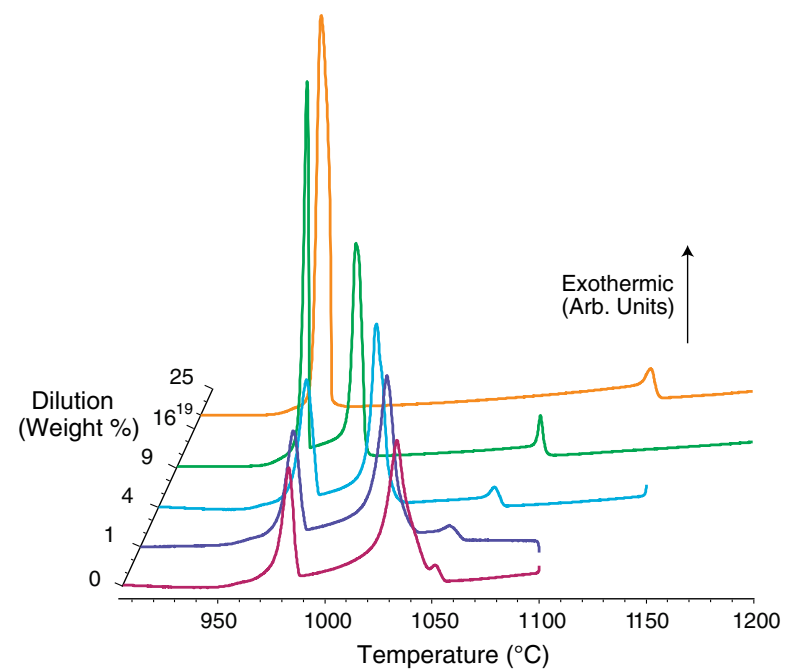

(a)

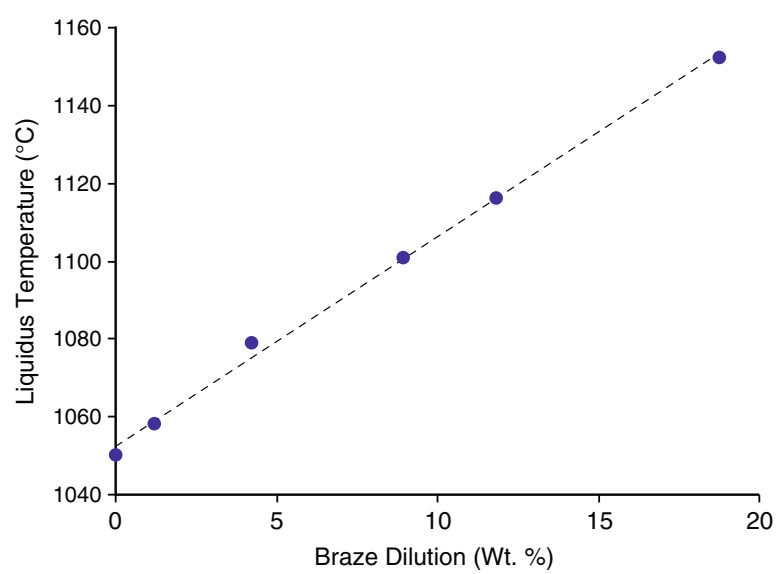

(b)

Fig. 2-(a) DSC cooling traces for dilutions of Nicrobraze 31. A series of 303 stainless steel additions (from 0 to 19 wt pct 303) were made to samples of braze alloy to explore the effect of substrate dissolution on thermal and microstructural properties. The three reactions in Nicrobraze 31 evolve with dilution to become two. (b) Liquidus temperature is plotted as a function of stainless steel addition. As isothermal solidification begins when the liquidus temperature reaches the brazing temperature (due to incorporation of dissolved steel), the fitted line can be used to predict substrate dissolution prior to isothermal solidification as a function of brazing temperature. 


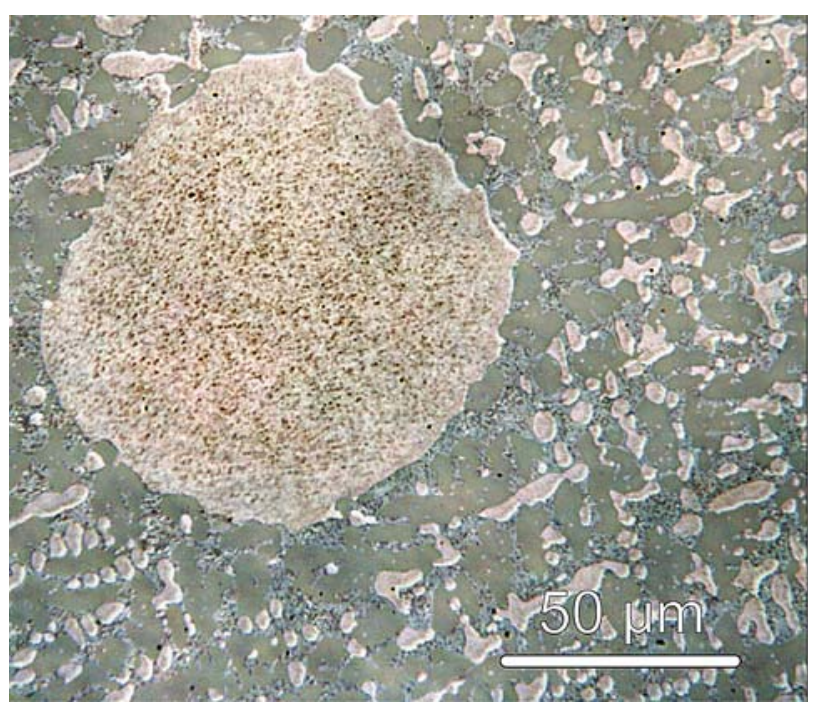

Fig. 3-Interrupted quench of 9 pct-303ss. Sample was encapsulated in quartz under $\mathrm{Ar}$ and cooled from $1100{ }^{\circ} \mathrm{C}$ to $1055^{\circ} \mathrm{C}$ (the liquidus for this alloy is $\left.\approx 1100^{\circ} \mathrm{C}\right)$; then it was water quenched. $\gamma$-(Ni) can be seen clearly as the primary phase.

The dilution of the braze causes the liquidus to rise by $5{ }^{\circ} \mathrm{C} / w_{s}$ (Figure 2(b)) (due to the addition of $\mathrm{Fe}$ ), while the two other reactions converge to a single exotherm (Figure 2(a)). The merging of the silicide into the terminal pseudo-eutectic reaction (Figure 2(a)) correlates with the near elimination of the massive silicide particles and the appearance of silicide in the lathlike eutectic microstructure (Figure 4). Concurrently, the Fe and $\mathrm{Ni}$ content of the primary $\gamma-(\mathrm{Ni})$ domains evolves monotonically (Figure 5(a)). The addition of stainless steel to the braze causes the solidification pathway below the liquidus to shift as follows: the original sequence comprising precipitation of $\gamma-(\mathrm{Ni})$ and silicide from the twofold saturation volume of the silicide reaction, followed by precipitation from the threefold saturation surface of the terminal pseudo-eutectic, is superseded by a saturation space shift wherein precipitation from the twofold silicide saturation volume is significantly reduced in favor of precipitation of all three solid phases from a single four-phase saturation path of the terminal pseudo-eutectic. The resulting microstructure simplifies to primary $\gamma-(\mathrm{Ni})$ in a three-phase field of a eutecticlike microstructure. This intermediate solidification sequence was unreported in previous work, wherein the silicide secondary reaction was eliminated entirely after 45 pct dilution, corresponding to a threephase terminal reaction. ${ }^{[10]}$

The drop quenching experiments reveal that a continuous layer of $\gamma$-(Ni) forms on the substrate 3 minutes after the specimen reaches the liquidus temperature, indicating that the dissolution reaction is complete at that time (Figure 6). Since the dissolution $\leftrightarrow$ reprecipitation reaction terminates with the onset of isothermal solidification, dissolution continues until the liquidus of the evolving liquid reaches the brazing temperature. Thus, the evolution of the liquidus temperature leads to a direct relationship between brazing temperature and

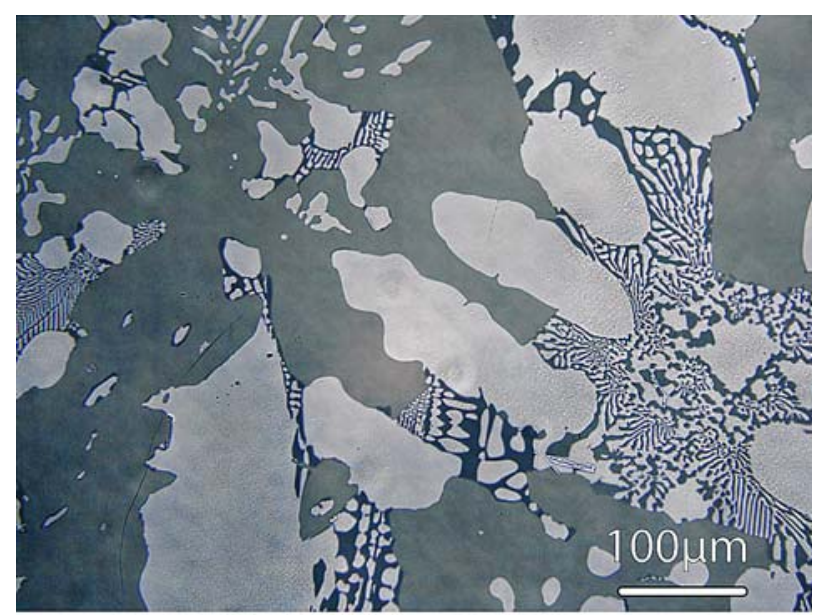

(a)

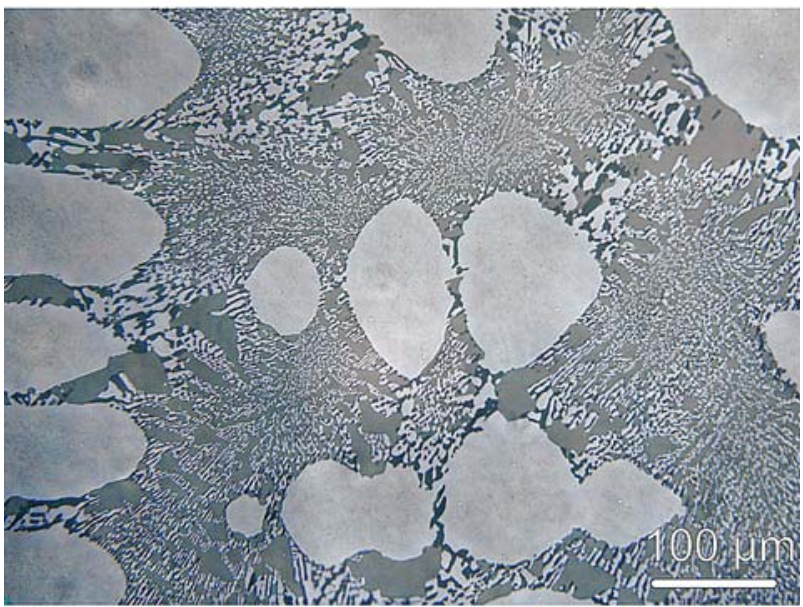

(b)

Fig. 4-Microstructural comparison of (a) Nicrobraze 31 to $(b)$ Nicrobraze 31 with 19 pct 303 ss. In (a), the three phases present are (i) the ductile $\gamma$-(Ni), which appears with bright contrast, present as both large primary grains and within the eutectic; (ii) the ternary phosphide, present as the second component of the eutectic having a darker appearance; and (iii) the quaternary silicide, which forms large irregular grains (with intermediate contrast) adjacent to both the primary $\gamma-(\mathrm{Ni})$ and the eutectic. The phases in (b) are equivalent, though the silicide grains are significantly smaller and greater fine eutectic is present.

early-stage recession (as distinct from the diffusioncontrolled pseudo-steady-state recession ${ }^{[10]}$ ) (Figure 2(b)).

Once the isothermal $\gamma$-(Ni) seals the substrate from contact with the liquid, solid-state diffusion through the $\gamma$-(Ni) controls continued evolution of the joint, leading to the formation of $\gamma-(\mathrm{Ni})$ cells, which then increase in size, with corresponding changes in composition (Figures 6 and 5(b)). Meanwhile, the large $\gamma$-(Ni) islands in the interior, which form on cooling, diminish rapidly and are eliminated entirely after 4 hours. Accordingly, the $\mathrm{Fe}$ and $\mathrm{Ni}$ contents (in mole fraction, $X$ ) of the primary $\gamma-(\mathrm{Ni})$ vary parabolically with time $(t)$ : $X_{\mathrm{Ni}, \mathrm{Fe}} \propto \sqrt{t}$, as expected for a diffusion-controlled process. Diffusion control is evident for all braze times shown, confirming that the $\gamma$-(Ni) layer on the substrate is effectively continuous after just 3 minutes. By invoking 


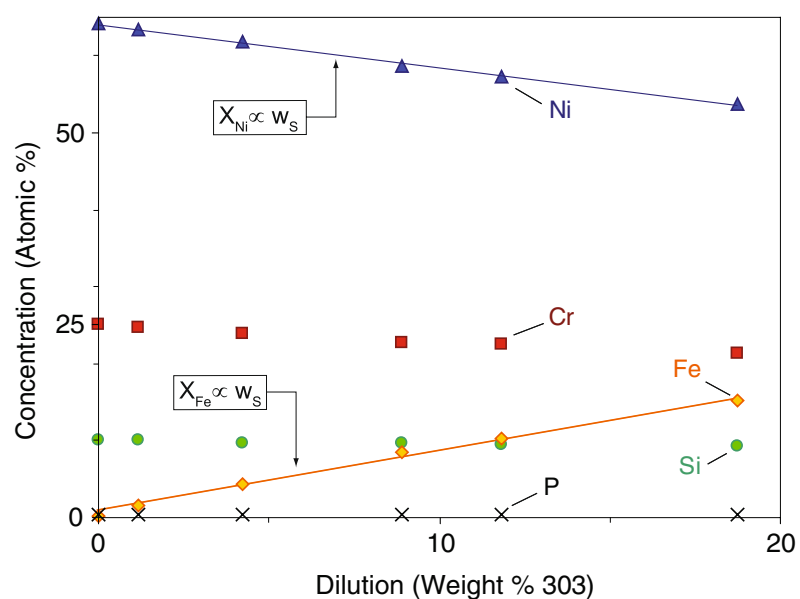

(a)

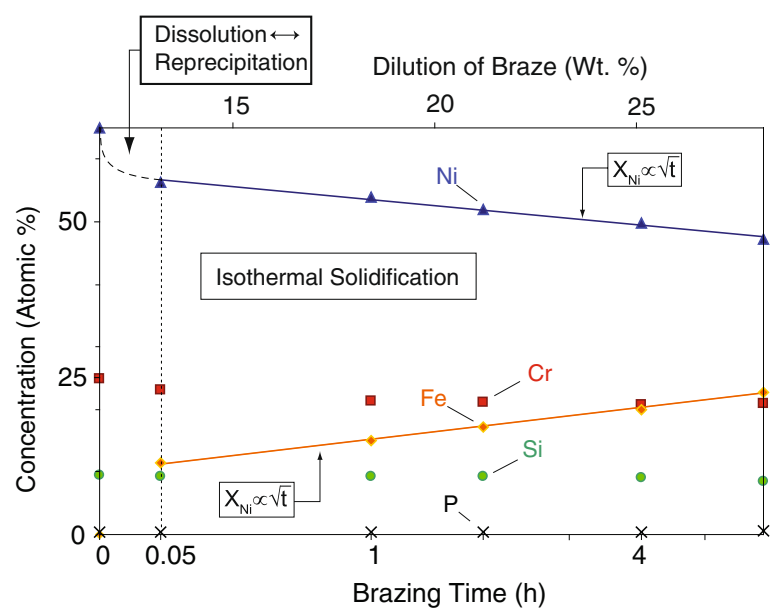

(b)

Fig. 5-Elemental composition (in atomic percent) of primary $\gamma-(\mathrm{Ni})$ as a function of $(a)$ dilution by 303 stainless steel and $(b)$ brazing time (measured from when the specimen reaches the braze liquidus) for a joint in 304 stainless steel. Dilution for the brazed joint has been calculated and plotted on the secondary axis of abscissae.

the proportionality, $X_{\mathrm{Ni}, \mathrm{Fe}} \propto w_{S}$, the dilution and brazing time can be plotted on complementary axes (Figure 5(b)). This construction allows correlation of total substrate recession to brazing time (at $1100{ }^{\circ} \mathrm{C}$ ), whereupon the dissolution $\leftrightarrow$ reprecipitation reaction leads to $\approx 12$ pct dilution of the braze alloy. This estimate is consistent with that predicted by the liquidus temperature; for a brazing at $1100{ }^{\circ} \mathrm{C}$, isothermal solidification commences at $\approx 9$ pct dilution.

\section{HEAT TREATMENTS}

Dissolution $\leftrightarrow$ reprecipitation occurs so rapidly that it is impractical to circumvent. However, by combining short brazing times with drop quenching, $\gamma$-(Ni) dendrites form and extend from the surface of the isothermal cells, preferentially oriented perpendicular to the joint (Figure 6). A heat treatment was developed to coarsen the elongated structure of the $\gamma$-(Ni) particles. The coarsening is conducted at $1015^{\circ} \mathrm{C}$, where there is sufficient liquid to facilitate rapid coarsening while avoiding remelting of the $\gamma-(\mathrm{Ni})$ dendrites. This temperature was chosen because the $\gamma-(\mathrm{Ni})$ dendrites are, in part, a product of coprecipitation with the silicide. This results in coarsening of the silicide as well as the $\gamma-(\mathrm{Ni})$, but coarsening above the silicide crystallization temperature is ineffective due to the low volume fraction of $\gamma$-(Ni).

The thermal profiles for quenching, $Q_{o}$, and coarsening, $Q_{C}$, as well as the ensuing microstructures, are depicted in Figure 7, relative to a standard braze cycle. Both exhibit centerline precipitation of $\gamma-(\mathrm{Ni})$. The microstructure of the $Q_{C}$ specimens comprises elongated $\gamma$-(Ni) domains that traverse the bond, albeit nonpercolating, surrounded by silicide islands and a eutectic microstructure. The coarsening takes place rapidly and is complete after only a few minutes; longer coarsening treatments result in nearly identical microstructures (not shown). Local microhardness measurements conducted within the $\gamma$-(Ni) domains by using a Vickers indenter at a 200-g load revealed a hardness, $H=2.4 \mathrm{GPa}$, indicative of a yield strength, $\sigma_{o} \approx 800 \mathrm{MPa}^{[15]}$ This strength is lower than that inferred from measurements on the eutectic $\gamma-(\mathrm{Ni})$ obtained by nanoindentation at much smaller penetrations, $\sigma_{o} \approx 1.3 \mathrm{GPa} .{ }^{[7]}$ This indentation size effect is attributed to the plasticity length scale. ${ }^{[16]}$ In the ensuing analysis of ductile-phase toughening, the smaller value will be used for the large domains and vice versa.

\section{FRACTURE RESISTANCE}

\section{A. Experimental Methods}

After brazing, double cantilever beam test configurations were machined by wire electrodischarge machining, followed by testing in displacement control in a servohydraulic frame instrumented with a load cell and a crack opening gage. Precracks were introduced using a $\mathrm{Si}_{3} \mathrm{~N}_{4}$ wedge, while constraining with a transverse clamp, and then delineated by heat tinting at $600{ }^{\circ} \mathrm{C}$ for 15 minutes. ${ }^{[7]}$ The fracture resistance was measured by wedge loading with the clamp removed. ${ }^{[7]}$ Crack profiles were investigated by optical and electron microscopy. The fracture surfaces were characterized by scanning electron microscopy (SEM), and transverse features were revealed by creating local cross sections with a focused ion beam (FIB). The testing and characterization were performed on specimens subject to brazing at $1100{ }^{\circ} \mathrm{C}$ for 3 minutes and drop quenching (the $Q_{o}$ treatment), as well as others subjected to additional coarsening at $1015^{\circ} \mathrm{C}$ for 10 minutes (designated $Q_{C}$ ).

\section{B. Measurements and Observations}

The fracture resistances measured for the two heat treatments are summarized in Table II. Evidently, both 

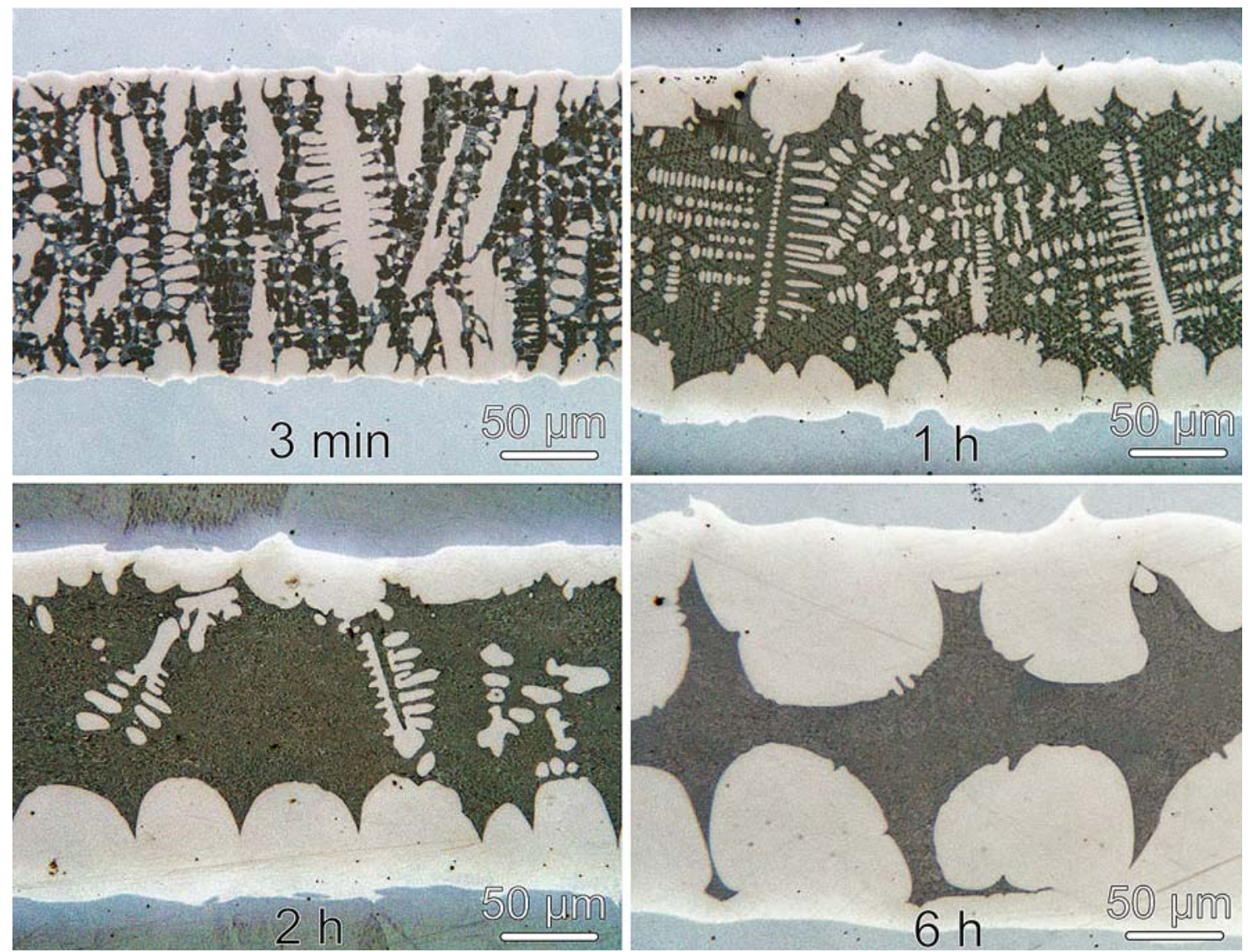

Fig. 6-Evolution of microstructure for joints brazed and drop quenched. Primary $\gamma$-(Ni) is evident as the large particles with bright contrast, both adjacent to the steel substrate and in the joint interior. The dark field along the center of the joint comprises a fine-grained combination of additional $\gamma-(\mathrm{Ni})$ and both intermetallics.

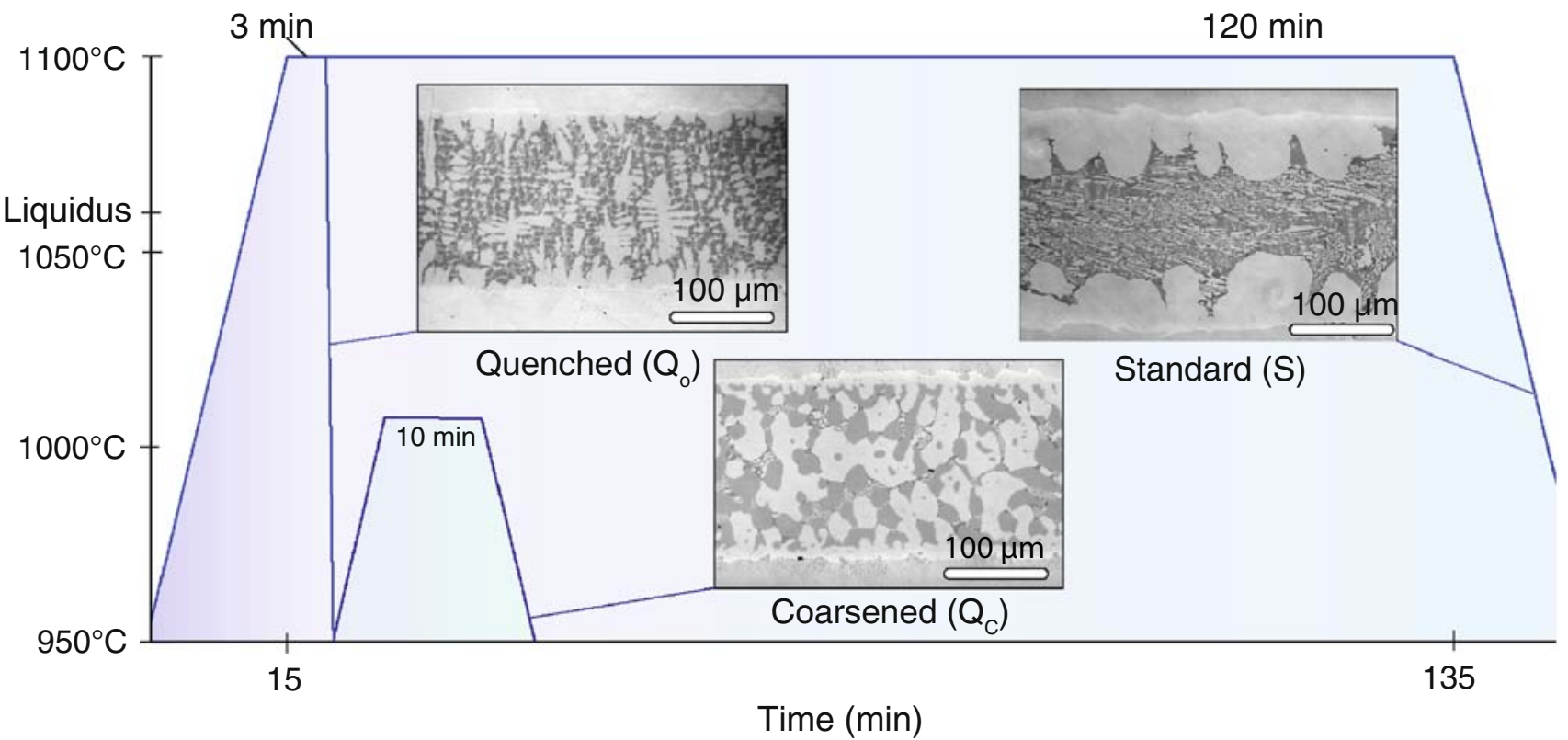

Fig. 7-Results of drop quench $\left(Q_{o}\right)$ and coarsening $\left(Q_{C}\right)$ braze schedules. Joint microstructures for the novel heat treatments are shown and compared with the previous work (S) (a joint brazed at $1100{ }^{\circ} \mathrm{C}$ for $2 \mathrm{~h}$ and cooled at $10{ }^{\circ} \mathrm{C} / \mathrm{min}^{[7]}$ ). The heat treatment profile is plotted for each sample type. Note the preferential perpendicular orientation of the $\gamma-(\mathrm{Ni})$ to the joint line in $Q_{o}$ and $Q_{C}$. 
Table II. Fracture Resistance of Joints Brazed with the Quenched $\left(Q_{o}\right)$, Coarsened $\left(Q_{C}\right)$, and Standard Braze Schedules $^{[7]}$

\begin{tabular}{lc}
\hline Heat Treatment & Fracture Resistance $\left(\mathrm{kJ} / \mathrm{m}^{2}\right)$ \\
\hline$Q_{o}$ & $1.68 \pm 0.1$ \\
$Q_{C}$ & $1.72 \pm 0.2$ \\
Standard & $0.93 \pm 0.08$ \\
\hline
\end{tabular}

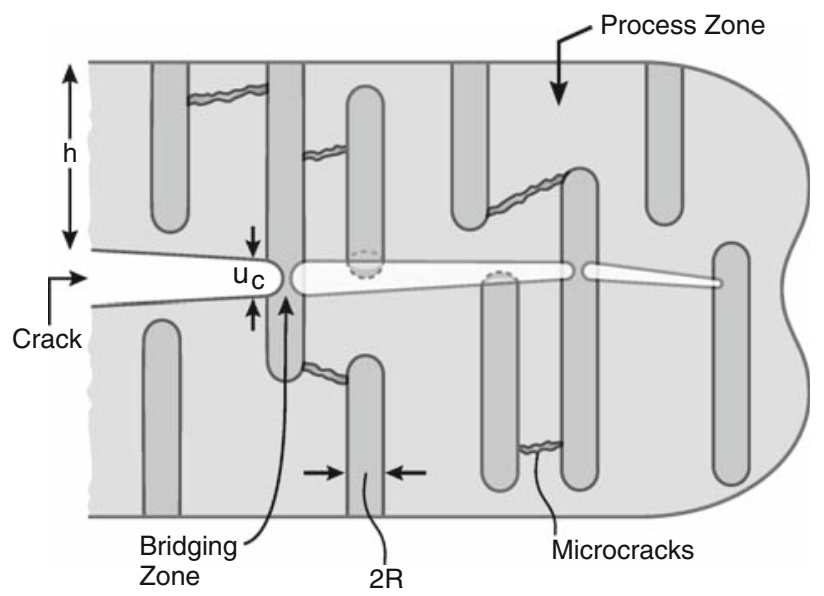

Fig. 8-Schematic of crack propagation. Primary $\gamma$-(Ni) contributes to the toughness in two modes: (1) the plastic stretch of the primary $\gamma$-(Ni) domains and (2) the plastic dissipation in the bypassed primary $\gamma-(\mathrm{Ni})$ particles. In addition to the primary crack, there is a process zone of microcracks with associated plastic stretch that contributes significant toughening. There is also smaller scale toughening due to the eutectic $\gamma-(\mathrm{Ni}),{ }^{[7]}$ not shown here.

thermal treatments produce bonds substantially tougher than those made using conventional brazing. Combined examination of the polished sides and of the fracture surfaces reveals that the mechanisms inhibiting crack extension are comparable for the two microstructures $\left(Q_{o}\right.$ and $\left.Q_{C}\right)$, albeit with some differences. A schematic (Figure 8) illustrates the predominant features.

For the quenched $Q_{o}$ microstructure, fracture is governed by a single dominant crack (Figures 9 and 10). Optical images of the side surfaces reveal that the crack propagates in a planar mode through the brittle intermetallics and intersects $\gamma$-(Ni) domains at two length scales (Figure 9(a)). At the larger scale, the crack traverses the percolating domains but, wherever possible, deviates around them. Higher resolution images indicate slip steps in the $\gamma$-(Ni), where it is intersected by the crack (Figures 9(b) and (c)). Some slip also occurs where the crack extends along the interfaces of the ductile domains (Figure 9(c)). The SEM images of the fracture surface (Figure 10) provide complementary information. The larger $\gamma$-(Ni) domains intersected by the crack plastically stretch and neck to a chisel point. Moreover, during this stretching process, localized, lateral cracks are induced in the surrounding intermetallic (Figure 10(a)). Those domains circumvented by the crack appear as domes on the fracture surface (Figure 10(a)). At higher resolution (Figure 10(b)), it is

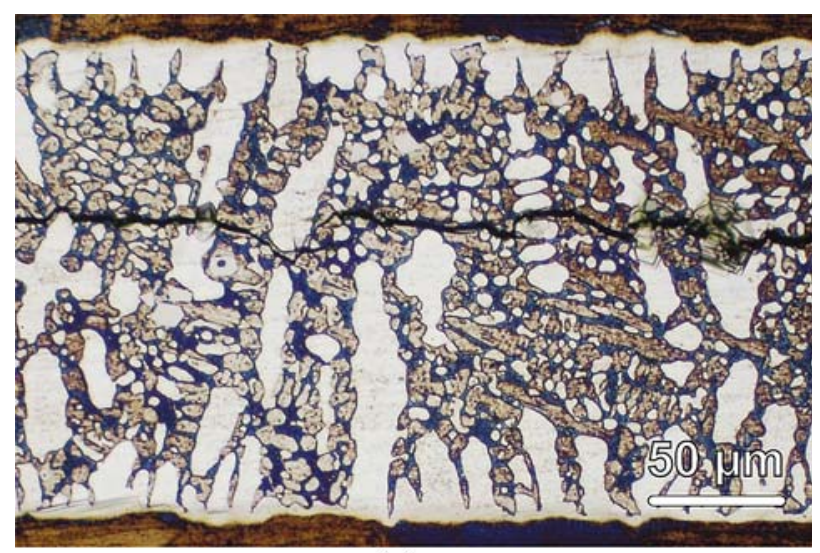

(a)

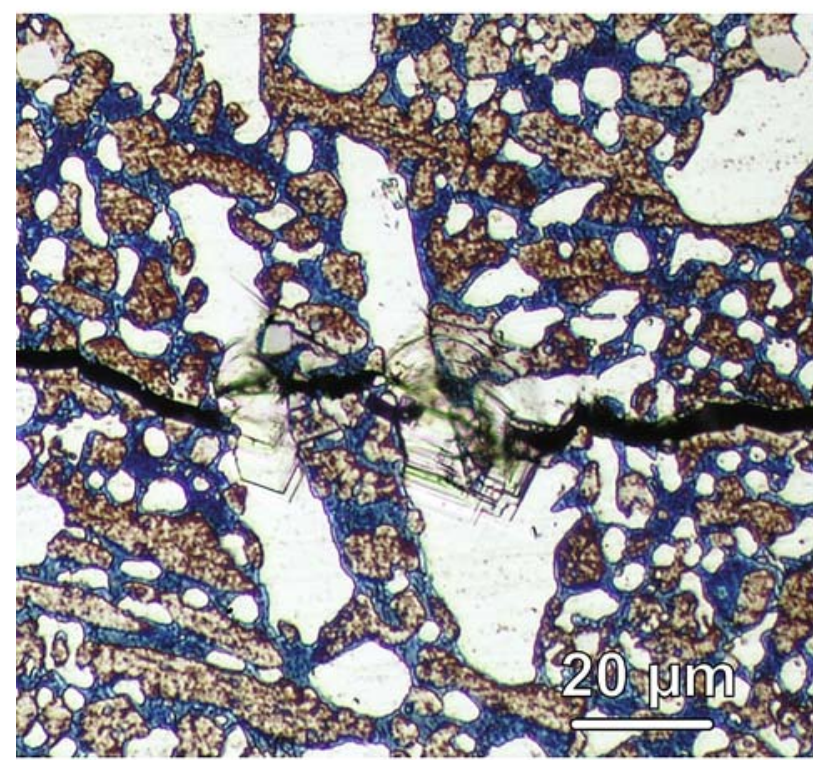

(b)

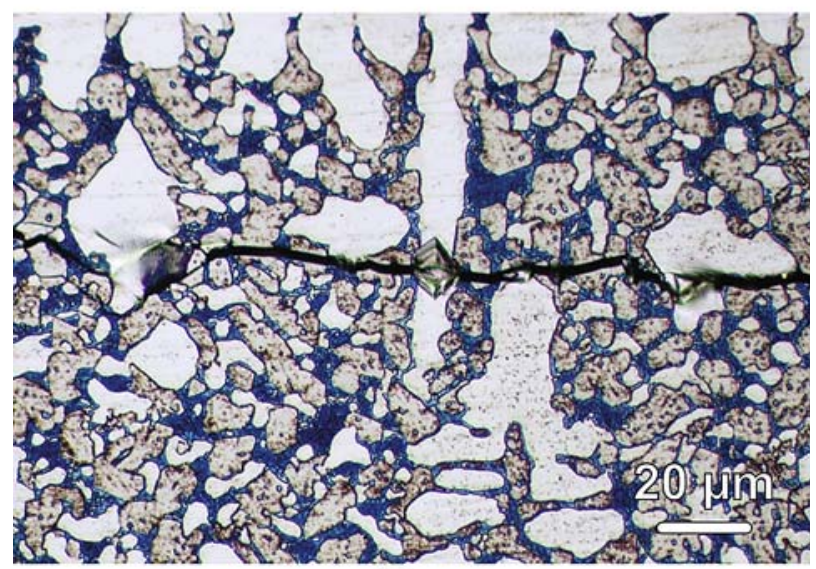

(c)

Fig. 9 - Surface cracks in $Q_{o}$. (a) Cracks in $Q_{o}$ propagate with minor deviations to avoid large $\gamma$-(Ni) domains. (b) The location of the intersection of the crack and the elongated primary $\gamma-(\mathrm{Ni})$ plastic deformation is evident as surface slip steps. (c) Domains that are bypassed also exhibit slip due to a plastic wake phenomenon.

apparent that the smaller $\gamma$-(Ni) domains within the eutectic also exhibit plastic stretch, with chisel-point rupture, as reported previously. ${ }^{[7]}$ Because the crack is 


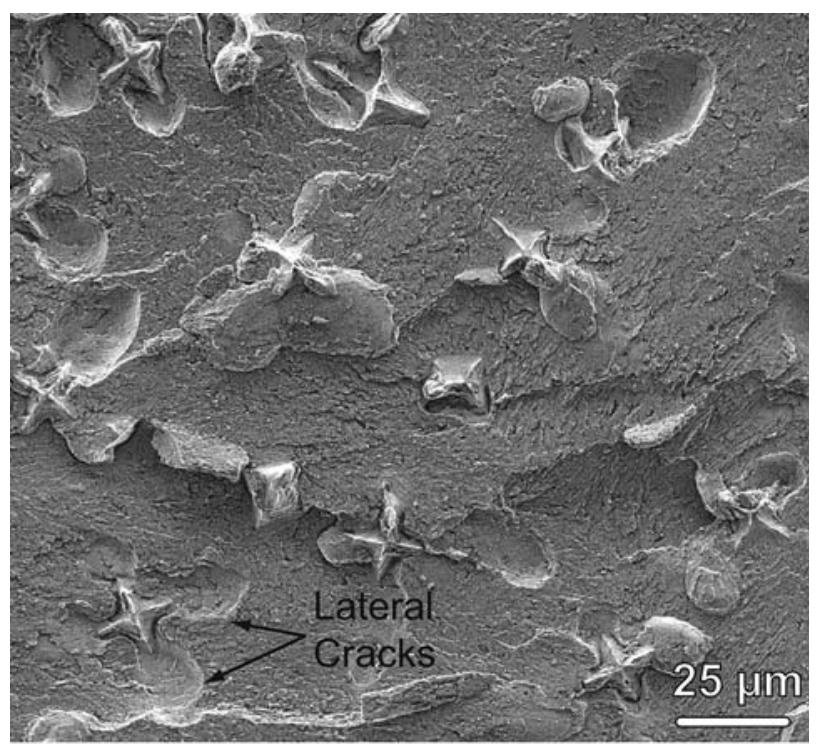

(a)

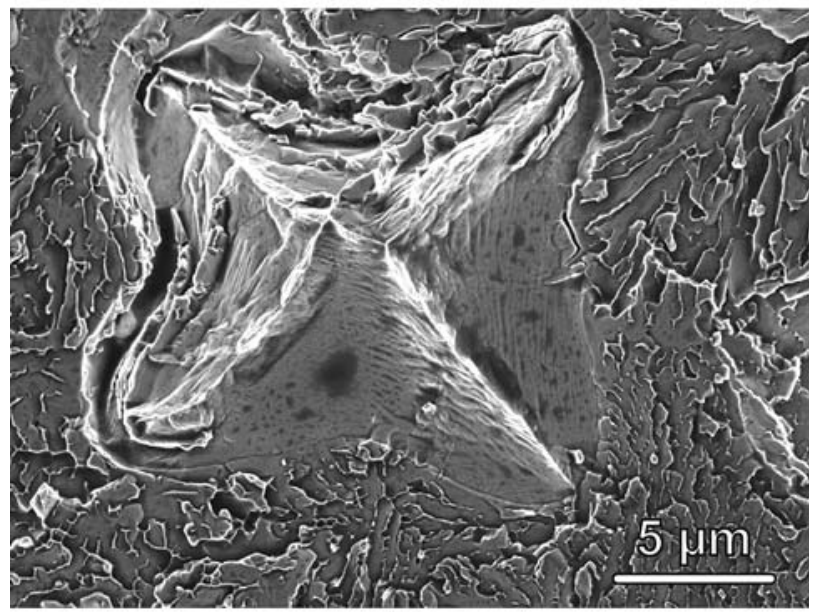

(b)

Fig. 10-Fractography of $Q_{o}$ specimen. (a) The plastic deformation of the $\gamma$-(Ni) is apparent as cruciform chisel points with the occasional lateral cracks. $\Gamma$-(Ni) domains that have been bypassed appear as domes. (b) Ductile tearing of primary $\gamma-(\mathrm{Ni})$ produces the large chisel points, while the network of failed eutectic $\gamma-(\mathrm{Ni})$ is apparent in the plane surrounding the primary domains.

planar, it is straightforward to conduct measurements of the plastically stretched primary ligaments on the fracture surface. For this purpose, the diagonals of the stretched ligaments are measured and an equivalent, circular area ascertained for each. These areas, deduced over a large region of the fracture surface (Figure 10(a)), provide the following ligament metrics: $f=0.07 \pm$ 0.005 and $R=8.8 \pm 0.2 \mu \mathrm{m}$. Cross sectioning using the FIB indicates that the ruptured ligaments exhibit plastic stretch, $u_{c} / R=0.5 \pm 0.07$, such that the work of rupture parameter, $\chi \approx 1.3$.

In the coarsened, $Q_{C}$ microstructure, some aspects of the response differ (Figures 11 through 13). The lower resolution SEM images of the side surface (Figure 11(a)) indicate that the fracture path is nonplanar and,

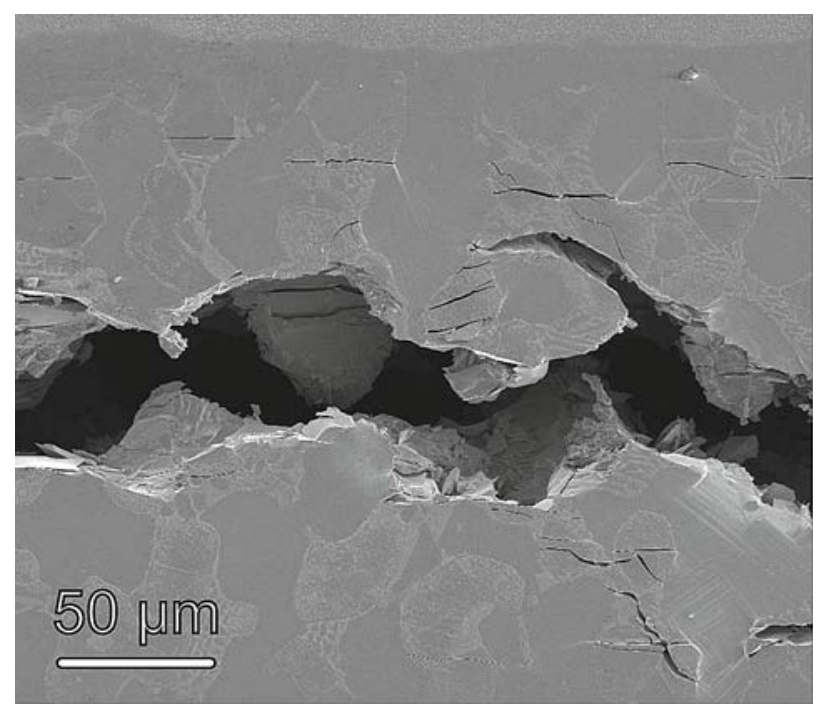

(a)

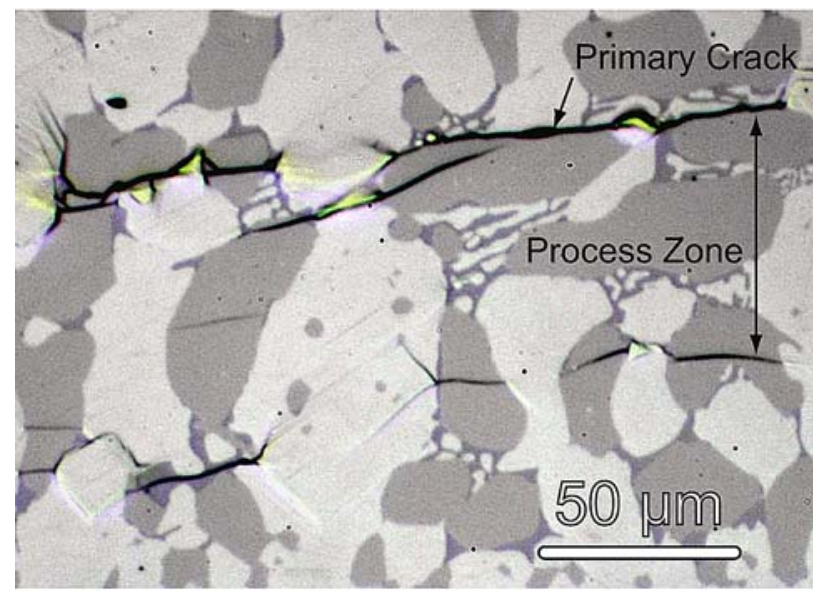

(b)

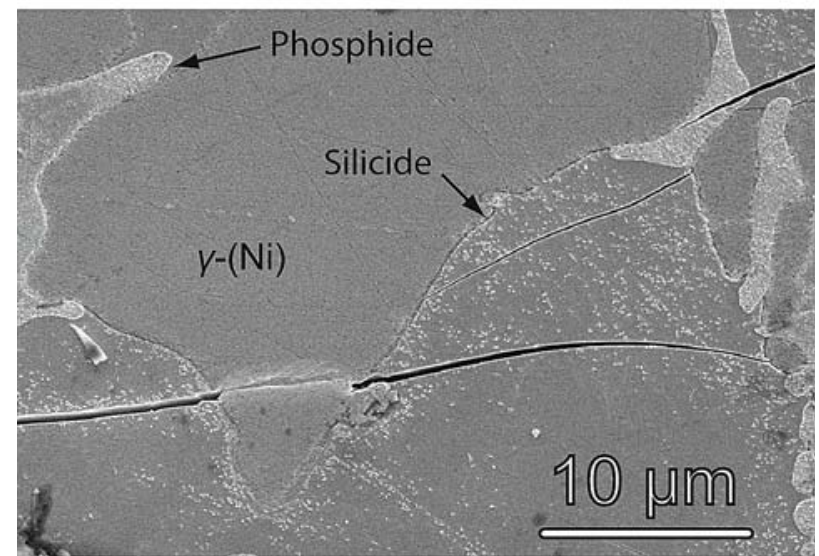

(c)

Fig. 11-Crack profile and process zone. (a) The primary crack is distinctly nonplanar, deviating to avoid large $\gamma$-(Ni) domains. An inelastic process zone on either side of the primary crack is apparent. (b) Optical image of the microcracks comprising the process zone adjacent to the primary crack. Microcracks propagate in the silicide and blunt into the $\gamma$-(Ni) with accompanying slip bands. $(c)$ SEM image of a plastic dissipation in the $\gamma$-(Ni) due to microcracking. Crack propagates in the silicide and phosphide and blunts into the $\gamma-(\mathrm{Ni})$. 


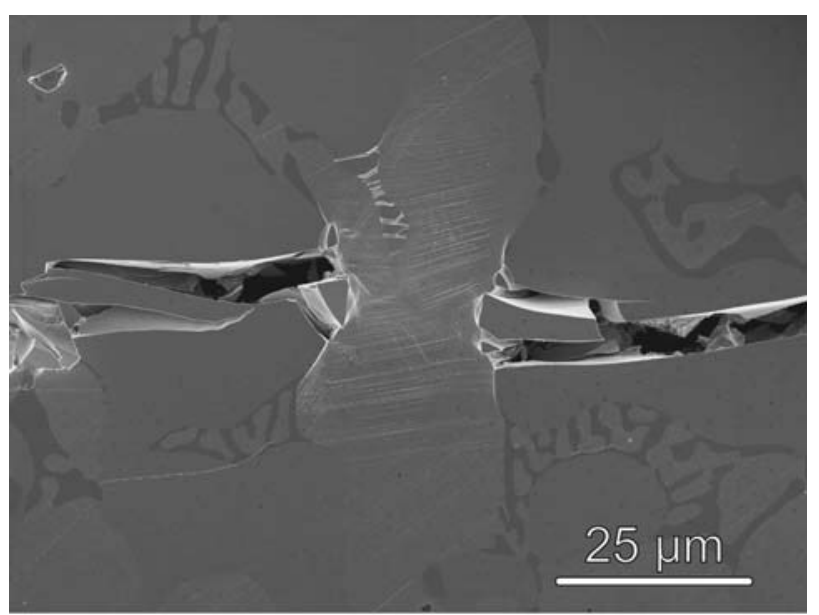

(a)

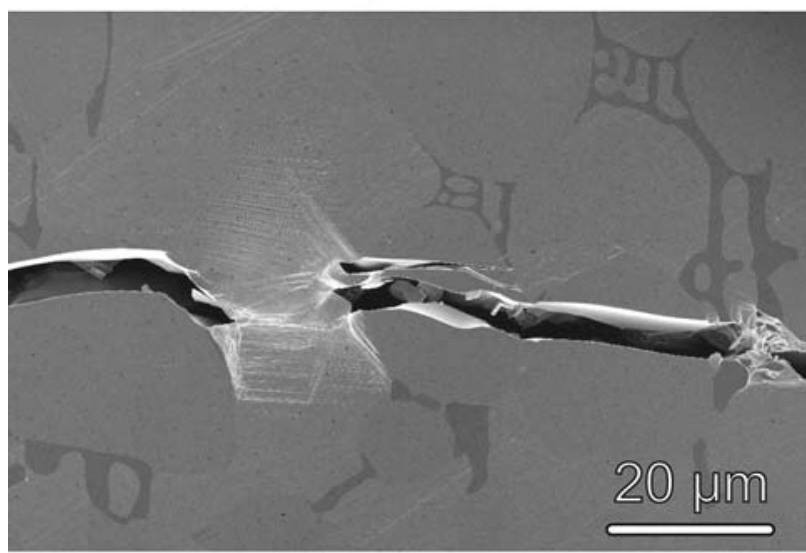

(b)

Fig. 12-Profile of stretched primary $\gamma$-(Ni) ligaments in coarsened, $Q_{C}$, specimens. (a) The crack intersects a primary $\gamma-(\mathrm{Ni})$ domain resulting in intense slip bands. (b) Plastic stretch ratios were measured at the onset of ductile rupture, $u_{c} / R \approx 0.5$.

moreover, that an inelastic process zone develops on both sides of the crack, having width $h \approx 50 \mu \mathrm{m}$. Optical and higher resolution SEM images (Figures 11(b) and (c)) indicate that this zone comprises discrete microcracks in the intermetallic, with associated blunting where arrested by the $\gamma$-(Ni), accompanied by slip bands. The residual opening displacement of the microcracks is of order $\delta_{\text {micro }} \approx 0.5 \mu \mathrm{m}$.

At locations where the crack intersects the larger $\gamma$-(Ni) domains, plastic stretch is accompanied by intense slip bands in the contiguous $\gamma$-(Ni), causing them to fail by shear, rather than necking (Figure 12). The SEM images of the fracture surface (Figure 13) affirm that the rupture of the $\gamma$-(Ni) domains occurs by a shear mechanism. It remains to provide a rationale for the change in the rupture mechanism in the ligaments upon aging, from tensile necking to shear banding. The area fraction and width of domains intersected by the crack are estimated from the images as $f \approx 0.03$ and $2 R \approx 30 \mu \mathrm{m}$. The plastic stretch on the verge of rupture is ascertained from the images on the side surface (Figure 12 (b)) as $u_{c} / R \approx 0.5$, with a work of rupture again, $\chi \approx 1.3$.

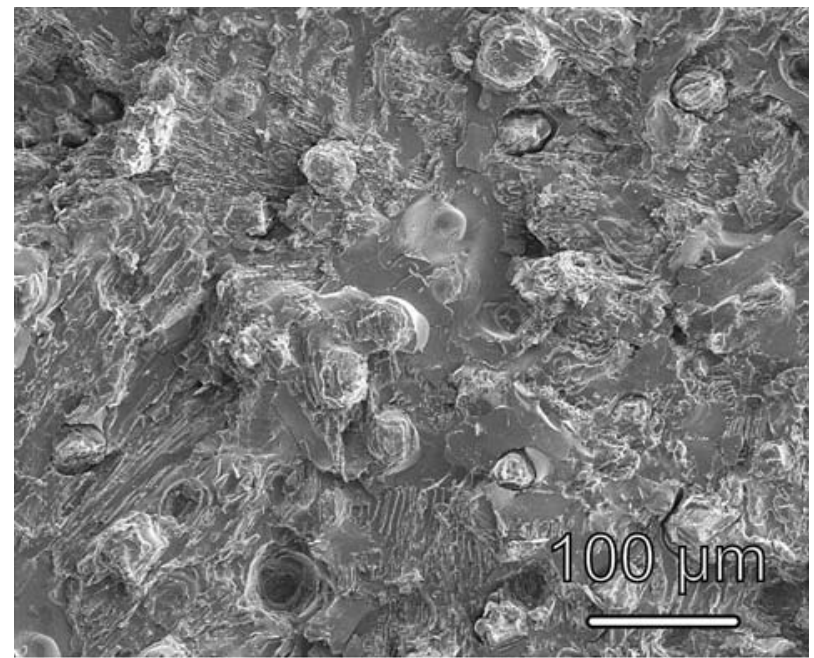

(a)

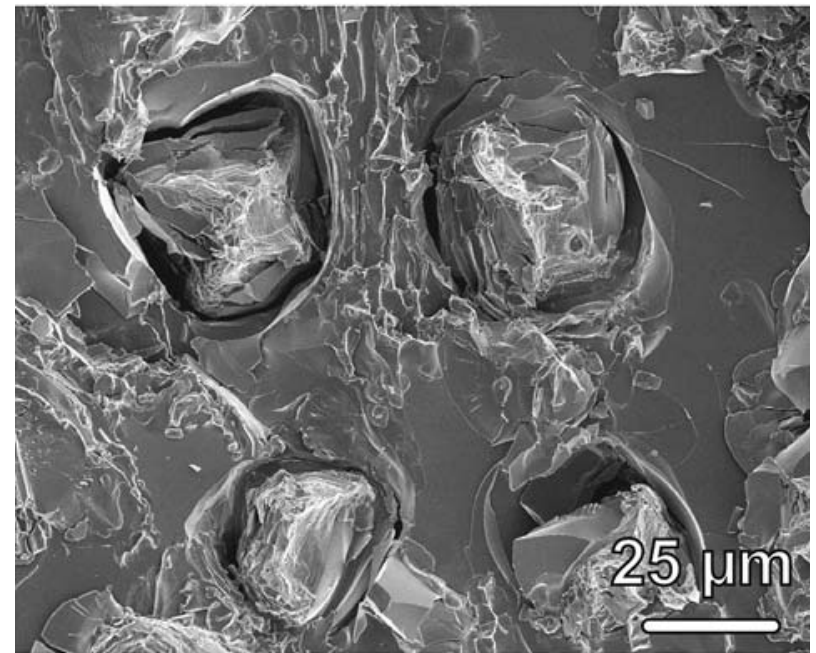

(b)

Fig. 13-Fracture surface of coarsened, $Q_{C}$, specimens. (a) The fracture surface is rough and nonplanar. Stretched ligaments appear as chisel points with a depressed border. Bypassed ligaments result in domes. (b) The stretched ligaments retain the cruciform chisel point morphology of $Q_{o}$, but it is less distinct.

\section{Interpretation}

The forgoing assessment suggests two contributions to the toughening: one from bridging and the other from a process zone (Figure 8 ). ${ }^{[14]}$ The bridging contribution is straightforward to interpret through the foregoing measurements of the plastic stretch. For the quenched, $Q_{o}$, microstructure, upon combining the inferred yield strength for the primary $\gamma-(\mathrm{Ni})$ domains, $\sigma_{o} \approx 800 \mathrm{MPa}$, with the ligament volume fraction and size yields a predicted toughening, $\Delta \Gamma_{s s}^{\text {primary }}=0.66 \pm 0.1 \mathrm{~kJ} / \mathrm{m}^{-2}$. This toughening is additive to that provided by the $\gamma-(\mathrm{Ni})$ in the eutectic, previously determined as ${ }^{[7]}$ $\Delta \Gamma_{s s}^{\text {eutectic }}=0.45 \mathrm{~kJ} / \mathrm{m}^{2}$. The total bridging contribution is thus $\Delta \Gamma_{s s}=1.1 \pm 0.2 \mathrm{~kJ} / \mathrm{m}^{2}$, appreciably lower than the measured toughness. The remainder is presumed to be due to the plastic dissipation in those $\gamma$-(Ni) domains circumvented by the crack, but not quantified. 
For the coarsened, $Q_{C}$, microstructure, the corresponding bridging contribution is somewhat smaller, $\Delta \Gamma_{s s}^{\text {primary }}=0.46 \mathrm{~kJ} / \mathrm{m}^{-2}$. Upon adding the toughening due to the $\gamma-(\mathrm{Ni})$ in the eutectic, the total bridging contribution becomes $\Delta \Gamma_{s s}=0.9 \mathrm{~kJ} / \mathrm{m}^{2}$. In this case, a process zone contribution can be estimated using ${ }^{[14]}$

$$
\Delta \Gamma_{\text {process }}=2 \sigma_{o} \int_{0}^{h} \varepsilon_{p l}(y) d y
$$

where $\varepsilon_{p l}$ is the inelastic strain at location $y$ within the zone and $h$ is the zone height. The opening displacements of the microcracks in the process zone suggest average plastic strains, $\bar{\varepsilon}_{p l} \approx \delta_{\text {micro }} / h$, whereupon the predicted toughening reduces to $\Delta \Gamma_{\text {process }} \approx 2 \sigma_{o} \delta_{\text {micro }}$. Based on the foregoing measurements of $\delta_{\text {micro, }}$, this contribution to toughening becomes $\Delta \Gamma_{\text {process }} \approx 0.8 \mathrm{~kJ} / \mathrm{m}^{2}$. Thus, the total toughening due to both ductile-phase mechanisms at both length scales, $\Delta \Gamma_{s s} \approx 1.7 \mathrm{~kJ} / \mathrm{m}^{2}$, accounts fully for the measured toughness.

While establishing a fully predictable contribution to toughening from the coarse ductile phases remains to be done, the foregoing assessment suggests that the bridging contribution is substantial. The implication is that, if percolation of the $\gamma$-(Ni) domains could be achieved by an appropriate thermal process, this contribution to the toughening could be increased further and greater robustness imparted to the joint.

\section{CONCLUDING REMARKS}

Counter to conventional wisdom, the deleterious influence of the intermetallic phases at the braze joint centerline has been mitigated by using very short brazing times. The resulting microstructure contains large $\gamma-(\mathrm{Ni})$ domains that provide ductile-phase toughening. The development of this beneficial microstructure has been based on analysis of transient liquid-phase phenomena, as well as the pseudo-steady-state diffusive processes. The present heat treatment is illustrative of an approach that exploits an understanding of microstructure evolution for enhancing the robustness of brazed joints. Further toughening might be achieved by eliminating the massive silicide and, most importantly, by achieving percolation of primary $\gamma-(\mathrm{Ni})$ across the joint. This might be realized by increasing the brazing temperature in order to eliminate the largest intermetallic particles, followed by heat treatments that enable $\gamma$-(Ni) percolation.

\section{OPEN ACCESS}

This article is distributed under the terms of the Creative Commons Attribution Noncommercial License which permits any noncommercial use, distribution, and reproduction in any medium, provided the original author(s) and source are credited.

\section{REFERENCES}

1. Z. Wei, K.P. Dharmasena, H.N.G. Wadley, and A.G. Evans: Int. J. Impact. Eng., 2007, vol. 34 (10), pp. 1602-18.

2. J.W. Hutchinson and Z.Y. Xue: Int. J. Mech. Sci., 2005, vol. 47 (4-5), pp. 545-69.

3. S.L.D.E. Lucato, J. Wang, P. Maxwell, R.M. McMeeking, and A.G. Evans: Int. J. Solids Struct., 2004, vol. 41 (13), pp. 3521-43.

4. F.W. Zok, H.J. Rathbun, Z. Wei, and A.G. Evans: Int. J. Solids Struct., 2003, vol. 40 (21), pp. 5707-22.

5. L. Valdevit, N. Vermaak, F.W. Zok, and A.G. Evans: J. Appl. Mech., 2008, vol. 75 (6), p. 061022.

6. H.N.G. Wadley, N.A. Fleck, and A.G. Evans: Compos. Sci. Technol., 2003, vol. 63 (16), pp. 2331-43.

7. N.R. Philips, M.Y. He, and A.G. Evans: Acta Mater., 2008, vol. 56 (17), pp. 4593-4600.

8. W.F. Gale and D.A. Butts: Sci. Technol. Weld. Join., 2004, vol. 9 (4), pp. 283-300.

9. X.W. Wu, R.S. Chandel, H.P. Seow, and H. Li: J. Mater. Process. Technol., 2001, vol. 113, pp. 215-21.

10. N.R. Philips, C.G. Levi, and A.G. Evans: Metall. Mater. Trans. A, 2008, vol. 39A, pp. 142-49.

11. M.F. Ashby, F.J. Blunt, and M. Bannister: Acta Metall., 1989, vol. 37 (7), pp. 1847-1857.

12. M.G. Mendiratta, J. Lewandowski, and D.M. Dimiduk: Metall. Trans. A, 1991, vol. 22A, pp. 1573-83.

13. B.D. Flinn, C.S. Lo, F.W. Zok, and A.G. Evans: J. Am. Ceram. Soc., 1993, vol. 76 (2), pp. 369-75.

14. A.G. Evans: J. Am. Ceram. Soc., 1990, vol. 73 (2), pp. 187-206.

15. D. Tabor: Br. J. Appl. Phys., 1956, vol. 7 (5), pp. 159-66.

16. M.R. Begley and J.W. Hutchinson: J. Mech. Phys. Solids, 1998, vol. $46(10)$, pp. 2049-68 